\title{
INTERPRETACIÓN SISTEMÁTICA DE LA NORMATIVA PENAL PERUANA SOBRE DELINCUENCIA ORGANIZADA: APUNTES DE SUS PRESUPUESTOS DOGMÁTICOS
}

\section{SYSTEMATIC INTERPRETATION OF PERUVIAN CRIMINAL LAW ON ORGANIZED CRIME: NOTES OF THEIR DOGMATIC SPECIFICATIONS}

\author{
Wendy Requejo Passoni ${ }^{1}$ \\ Abogada \\ Universidad de San Martín de Porres \\ https://orcid.org/0000-0001-9952-2199 \\ wendyrequejopassoni@gmail.com
}

Perú

\section{SUMARIO}

- Introducción

- Cuestiones terminológicas

- Evolución legislativa de la delincuencia organizada

- Definición legal de organización delictiva

- Figuras típicas relativas a la delincuencia organizada

- Síntesis de los presupuestos dogmáticos para la interpretación sistemática

- Conclusiones

- Fuentes de información.

\section{RESUMEN}

El objeto de estudio de este trabajo recae en la legislación peruana sobre delincuencia organizada. El objetivo principal de la investigación consiste en identificar los presupuestos dogmáticos esenciales para la interpretación sistemática de sus enunciados. Los materiales consultados han sido las leyes penales, la doctrina y la jurisprudencia nacional. A partir del análisis de la legislación, se advierte que dichos presupuestos consisten en: (i) establecer un glosario sobre las expresiones a emplearse (ii) determinar la evolución de los instrumentos legales más relevantes (iii) descomponer a la delincuencia organizada en un esquema de tipos autónomos de organización, subtipos específicos agravados, especiales circunstancias genéricas de agravación y tipos autónomos de banda. Finalmente, se advierte que adoptar una perspectiva fraccionaria de esta normativa puede conllevar a diversidad de posturas que menoscaban a la seguridad jurídica.

\section{ABSTRACT}

The object of this study is the Peruvian legislation on organized crime. The main objective of the research is to identify the dogmatic assumptions essential for the systematic interpretation of its statements. The materials consulted were criminal laws, doctrine and national jurisprudence. From the analysis of the legislation, it is noted that these budgets consist of: (i) establishing a glossary of the terms to be used (ii) determining the evolution of the most relevant legal instruments (iii) break down organised crime into a scheme of autonomous types of organisation, aggravated specific subtypes, special generic aggravating circumstances and autonomous types of gang. Finally, it is noted that adopting a fractional perspective of this regulation can lead to a diversity of positions that undermine legal certainty.

1 Servidora púbica de la Segunda Fiscalía Suprema Transitoria Especializada en delitos cometidos por Funcionarios Públicos 


\section{PALABRAS CLAVE}

Crimen organizado; banda; organización; asociación ilícita.

\section{KEYWORDS}

Organized crime; gang; organization; criminal association.

\section{INTRODUCCIÓN}

Hoy en día, la criminalidad organizada sigue siendo un tema pendiente en la agenda pública peruana, muestra de esto es la aprobación de la Política Nacional Multisectorial de lucha contra el Crimen Organizado para el periodo 2019-2030 (Decreto Supremo N ${ }^{\circ}$ 17-2019IN). Iniciativa con la que se busca implementar una política pública general sobre la materia.

En el Perú, reportes oficiales describen al fenómeno local de esta forma de criminalidad como un objeto de estudio complejo. Así, en el año 2017 el Ministerio del Interior informó que las organizaciones delictivas nacionales se caracterizan por cometer delitos económicos o violentos, ejercer control territorial en varias regiones del país, mantener contacto con presidiarios y autoridades en funciones, y desarrollar complejas estructuras en la distribución de tareas y funciones.

Naturalmente, estarepresentación del fenómeno social influye en el ejercicio del ius puniendi, por un lado, en la legislación penal sustantiva, y por otro, en la interpretación de dichos enunciados. En lo relativo a la legislación, es cierto que la Ley contra el crimen organizado $\mathrm{N}^{\circ} 30077$ y el propio artículo 317 del Código Penal carecen de técnica legislativa adecuada, y por tanto, ameritan futuras reformas legales, tal como se recomienda en el sexto lineamiento de la Política Nacional Multisectorial antes citada.

Empero, más controversial aún es el ámbito de la interpretación jurídica, donde además de lidiar con las deficiencias del texto legal, debe asumirse la tarea de identificar, analizar, discernir y sistematizar cada una de las abundantes y dispersas definiciones y figuras típicas de la delincuencia organizada. La problemática se suscita cuando el intérprete prescinde de la interpretación sistemática, o cuando omite contextualizar su alcance a algún periodo de vigencia determinado, propiciando con ello un estado de incertidumbre jurídica.

A pesar de la existencia de abundantes textos y decisiones jurisprudenciales sobre organizaciones delictivas, son escasos aún los estudios que promuevan una interpretación sistemática de estos enunciados. Precisamente, el objetivo de este trabajo consiste en identificar los presupuestos dogmáticos aplicados a la interpretación sistemática de la normativa nacional sobre delincuencia organizada; para estos fines, se ha consultado las leyes penales, doctrina y jurisprudencia peruana relevante sobre organizaciones $\mathrm{y}$ bandas delictivas. Cabe agregar, que esta puntual investigación se justifica en la necesidad de uniformizar criterios, como medio para preservar la seguridad jurídica.

Respecto a la estructura de este artículo, inicia con una breve descripción de la terminología a emplearse. Seguidamente se analiza la evolución legislativa sobre la materia, identificando tres momentos importantes. En la siguiente sección, se examina la definición legal de organización delictiva y cada uno de sus componentes, además de las figuras típicas relativas a la delincuencia organizada. Finalmente, se argumenta la conveniencia de abordar a esta legislación como un subsistema jurídico-penal especializado.

\section{CUESTIONES TERMINOLÓGICAS}

Al consultar la literatura sobre criminalidad organizada saltan a la vista numerosas palabras y expresiones que en apariencia aluden a un mismo fenómeno, sin embargo, examinadas con detenimiento es posible discernir sustanciales diferencias. Para una mejor comprensión, propongo agruparlas según la rama del conocimiento del cual derivan, esto es, en criminológicas y jurídicas.

Al primer grupo conciernen los términos macro criminalidad, crimen organizado y criminalidad organizada. Sobre los cuales puede aseverarse que «la macro criminalidad comprende diversos fenómenos en los que intervengan pluralidad de individuos, pero solo uno de ellos es el crimen o la criminalidad organizada» (Requejo, 2019, pág. 73). De acuerdo a la criminología el fenómeno criminal puede ser explorado desde un enfoque empírico multidisciplinario, por tanto, para 
determinar si un grupo u organización es delincuencia organizada, cabe apreciar ciertas características ajenas a los propios conceptos jurídicos (Merino \& Paíno, 2017, pág. 31). Por ejemplo, según López-Muñoz (2015) la criminalidad organizada empíricamente destaca por su acceso a medios personales y materiales, coberturas, uso de la violencia, valores criminales, ataque al Estado y estructuras de asentamiento criminal (pág. 12-22), descripción que difiere respecto a los presupuestos legales del artículo 317 del Código Penal.

Atendiendo a dicha razón es que el uso de estos vocablos debería reservarse a ámbitos de investigación social, y excepcionalmente admitirse en otras disciplinas, cuando se haga referencia al objeto de estudio criminológico. En consecuencia, cuando se alude al objeto de estudio de una investigación jurídica es preferible emplear la locución delincuencia y no criminalidad organizada.

Al segundo grupo pertenecen los vocablos organización delictiva ${ }^{2}$, grupo delictivo organizado $^{3}$, asociación estructurada y grupo delictivo estructurado ${ }^{4}$, todos derivados de instrumentos jurídicos supranacionales o regionales, al igual que las expresiones españolas organización y grupo criminal ${ }^{5}$. En todos estos casos es claro que un mismo término no posee un significado equivalente en cualquier parte del mundo, por ende, lo recomendable es contextualizar su uso.

Esta misma lógica es aplicable al ordenamiento jurídico peruano, donde tampoco cabe admitir la equivalencia absoluta entre organización criminal, asociación ilícita ${ }^{6}$, asociación delictiva $^{7}$, agrupación ilícita $^{8}$, agrupación

2 Véase el artículo 1 de la Acción Común 98/733/JAI (DOCE, núm. L 351/1) del Consejo Europeo.

3 Véase el artículo 2 literal a) de la Convención de Palermo de las Naciones Unidas.

4 Véase el artículo 1 de la Decisión Marco 2008/841/JAI del Consejo Europeo.

5 En la legislación española los delitos de organización criminal y grupo criminal (artículo 570 bis. 1 y 570 ter del Código Penal reformado por LO 5/2010, respectivamente), coexisten junto al delito de asociaciones para delinquir (artículo 515.1 y 5 del Código Penal), circunstancia que no se presenta en la normativa peruana.

6 Véase la sumilla de la primera modificación del artículo 317 del Código Penal (Ley $\mathrm{N}^{\circ}$ 28355).

7 Véase la primera reforma del artículo 257-A del Código Penal (Ley $\mathrm{N}^{\circ}$ 27593).

8 Véase la sumilla del texto original del artículo 317 del criminal $^{9}$ ni banda criminal $^{10}$, pues cada una de estas expresiones responde a un enunciado legal vigente en un periodo determinado, cuyo concreto alcance se abordará con detenimiento más adelante.

Sin perjuicio de ello quisiera desarrollar un breve comentario sobre la impropiedad de añadir el calificativo "criminal". Puesto que el código penal vigente adopta una división bipartita (delitos y faltas) y no tripartita (crímenes, delitos y faltas) de las infracciones penales, insistir en esta denominación carece de propósito; por ello sostengo que, en lo pertinente, toda referencia legal a lo criminal debe ser sustituida por lo delictivo, así, sería organización delictiva en vez de organización criminal (Requejo, 2019, pág. 77). Sobre esto último, cabe precisar qué organización delictiva es un elemento normativo y no un sujeto con capacidad de acción.

No obstante, la terminología jurídica no se agota en la legislación penal, sino que también abarca los pronunciamientos de los tribunales de justicia.

En la década de los noventa, la jurisprudencia nacional solía reducir a la delincuencia organizada a delitos violentos y económicos cometidos por agrupaciones, es decir, el factor determinante se hallaba en la ejecución del programa delictivo ${ }^{11}$. Progresivamente esta perspectiva fue cambiando, de modo que una década más tarde era claro que para calificar un caso como delincuencia organizada bastaba con la sola existencia del ente colectivo ${ }^{12}$, debiendo examinarse con rigor los vínculos entre sus miembros ${ }^{13}$ y la forma jerarquizada de su estructura ${ }^{14}$. Actualmente, la delincuencia organizada comprende tanto a las agrupaciones que han desarrollado su programa delictivo como a aquellas que aún $\mathrm{no}^{15}$, pudiendo

Código Penal (Ley N² 25362).

9 Véase la sétima modificación del artículo 152 del Código Penal (D. Leg. $N^{\circ} 982$ ).

10 Véase al artículo 317-B (D. Leg. $\left.\mathrm{N}^{\circ} 1244\right)$.

11 Véase Corte Suprema de la República, Recurso de Nulidad $N^{\circ}$ 492-1999 CONO NORTE.

12 Véase Corte Suprema de la República, Acuerdo Plenario Nº42006.

13 Véase Corte Suprema de la República, Recurso de Nulidad N ${ }^{\circ}$ 889-2010 Lima.

14 Véase Corte Suprema de la República, Recursos de Nulidad N ${ }^{\circ}$ 3308-2010, 1109-2009 Lima y 2780-2009 LambaYEQue.

15 Véase Corte Suprema de la República, Acuerdo Plenario Nº82007. 
tratarse en ambos casos de estructuras estables o permanentes ${ }^{16} \mathrm{y}$ flexibles ${ }^{17}$.

Aunado a ello, la jurisprudencia contemporánea ha profundizado en la integración de la legislación y la criminología, ello se hace más perceptible a través de la aplicación de máximas de la experiencia en los juicios penales ${ }^{18}$, concretamente al aludir a la clandestinidad ${ }^{19}$, impunidad $^{20}$ y peligrosidad $^{21}$ de las organizaciones delictivas. Esto ha permitido renovar el entendimiento de la criminalidad organizada, pues como anteriormente se describió, se trata de un fenómeno social complejo y dinámico.

Retomando, por delincuencia organizada se entiende a la representación de la criminalidad organizada en el ámbito jurídico, de ahí que se la describa como un término proveniente del derecho (Reátegui, 2017, p. 281).

\section{EVOLUCIÓN LEGISLATIVA DE LA DELINCUENCIA ORGANIZADA}

Ciertamente, la persecución a miembros de bandas, cuadrillas u organizaciones delictivas no es una preocupación inédita del nuevo siglo, antes bien, ya en el Código Penal de Santa Cruz de 1837 existía una prototípica figura de asociación ilícita (Zúñiga, 2016, pág. 49); sin embargo, la legislación penal sobre delincuencia organizada, tal como actualmente la conocemos, se registra por primera vez en 1991. Desde entonces su evolución legislativa ha transitado por tres periodos.

\section{Primer periodo: Código Penal de 1991 y sus reformas}

Durante los primeros años de vigencia del actual cuerpo legal, el tratamiento punitivo contra la criminalidad organizada principalmente

\footnotetext{
16 Véase Corte Suprema de la República, Recurso de Nulidad N ${ }^{\circ}$ 601-2015 Junín, Casación N² 421-2015 AREquipa.

17 Véase Corte Suprema de la República, Recurso de Nulidad $N^{\circ}$ 886-2014 Lima.

18 Véase Corte Suprema de la República, Recurso de Nulidad N ${ }^{\circ}$ 1531-2014 Lima, 2367-2016 NACIONAL y CASACIÓN N 626-2013 Moquegua.

19 Véase Corte Suprema de la República, Recurso de Nulidad $\mathrm{N}^{\circ} 1731-2014$ Lima.

20 Véase Corte Suprema de la República, Recurso de Nulidad N ${ }^{\circ}$ 583-2011 AyACUCHO.

21 Véase Corte Suprema de la República, Recurso de Nulidad N ${ }^{\circ}$ 2373-2015 CALLAO.
}

consistió en cualificar los delitos cometidos por miembros, jefes, cabecillas o dirigentes de organizaciones delictivas; siguiendo la conocida fórmula de los subtipos específicos agravados $^{22}$. Igualmente se criminalizó el acto de «formar parte de una organización de dos o más personas destinada cometer delitos (...) por el sólo hecho de ser miembro de la misma» (texto original del artículo 317). Descripción que recibió la denominación de delito de asociación ilícita para delinquir, y que cuenta con subtipos específicos agravados según la tendencia delictiva del ente colectivo, por ejemplo, cuando el agente integra una organización destinada a cometer delitos contra la humanidad, seguridad y tranquilidad pública. Es menester mencionar que, en este periodo asociación delictiva, agrupación ilícita, agrupación criminal y asociación ilícita son vocablos equivalentes.

En definitiva, en este periodo la legislación sobre delincuencia organizada es aún elemental, pues sus enunciados son pocos y su interpretación no conlleva mayores complicaciones.

\section{Segundo periodo: Ley contra el crimen organizado $\mathrm{N}^{\circ} \mathbf{3 0 0 7 7}$}

A mediados del 2013 el Congreso de la República aprobó el texto sustitutorio de la Ley contra el crimen organizado $\mathrm{N}^{\circ} 30077$, vigente desde el 1 de julio del 2014. La promulgación de esta ley marca el inicio de un nuevo periodo, pues a través de ella el Estado peruano asume su compromiso de adaptar la legislación penal a los estándares de la Convención de Palermo, suscrita desde el 2001.

Con relación al contenido de la Ley $\mathrm{N}^{\circ} 30077$, incorpora por primera vez una definición legal de organización delictiva. Describiéndola como:

Cualquier agrupación de tres o más personas que se reparten diversas tareas o funciones, cualquiera sea su estructura y ámbito de acción, que, con carácter estable o por tiempo indefinido, se crea, existe o funciona, inequívoca y directamente, de

22 En un principio los delitos cualificados por la calidad del sujeto activo eran exclusivamente de indole lucrativa, tiempo después este criterio fue descartado; llegándose inclusive a prever una consecuencia jurídico-penal más grave para aquel integrante cometiese delitos contra bosques y formaciones rocosas (artículo 310-C incorporado por la Ley $\left.\mathrm{N}^{\circ} 29263\right)$. 
manera concertada y coordinada, con la finalidad de cometer uno o más delitos graves señalados en el artículo 3 de la presente Ley (artículo 2.1).

Cabe puntualizar que la organización delictiva del artículo 2.1 y la asociación ilícita/ organización del artículo 317 modificado por la Ley $\mathrm{N}^{\circ} 30077$, no aluden a un mismo fenómeno delictivo. Para empezar, el diario de debates del Congreso peruano reseña que la intención de los legisladores fue conservar al artículo 317 como una manifestación menos compleja de las organizaciones delictivas; asimismo, la cantidad mínima de integrantes del artículo 2.1 y del artículo 317 es discrepante; por último, la definición de la ley especial hace referencia a ciertos delitos graves, los cuales tampoco coinciden con las formas agravadas del artículo 317. Es decir, por lo menos durante este periodo, existen motivos para aseverar que se tratan de diferentes figuras legales (Requejo, 2019, pág. 47).

Otro aspecto relevante de la Ley $\mathrm{N}^{\circ} 30077$ es que, al reformar al artículo 317 del código penal, criminalizó nuevos comportamientos típicos, como constituir y/o promover una asociación ilícita/organización; además, de subtipos específicos agravados, según el rol desempeñado por el sujeto activo, sea como líder, jefe, dirigente o financista.

\section{Tercer periodo: Decreto Legislativo $\mathbf{N}^{\circ}$ 1244 que fortalece a la Ley contra el crimen organizado}

Este periodo data del 29 de octubre del 2016, con la promulgación del Decreto Legislativo $\mathrm{N}^{\circ}$ 1244. Mediante el cual se modifica por última vez al artículo 317 del Código Penal, bajo los siguientes términos:

El que promueva, organice, constituya, o integre una organización criminal de tres o más personas con carácter estable, permanente o por tiempo indefinido, que, de manera organizada, concertada o coordinada, se repartan diversas tareas o funciones, destinada a cometer delitos será reprimido con pena privativa de libertad no menor de ocho ni mayor de quince años y con ciento ochenta a trescientos sesenta y cinco días - multa, e inhabilitación conforme al artículo $36^{\circ}$, incisos 1$\left.\left.), 2\right), 4\right)$ y 8 ).

En la siguiente sección se examinará pormenorizadamente cada elemento de dicho texto legal. No obstante, cabe destacar que la actual versión del artículo 317 ya no es discrepante de la organización delictiva del artículo 2.1 de la Ley $\mathrm{N}^{\circ} 30077$, por el contrario, hoy en día ambos enunciados se complementan, ya que hacen referencia a un mismo fenómeno delictivo.

\section{DEFINICIÓN LEGAL DE ORGANIZACIÓN DELICTIVA}

De conformidad con la Ley $\mathrm{N}^{\circ} 30077$, una organización delictiva es la agrupación de individuos que cuenta con directrices internas, que mantiene vigencia, además de indeterminación en torno a su desarrollo estructural y/o expansión territorial. Aunado a ello, de acuerdo al vigente artículo 317 , son rasgos distintivos del colectivo, su permanencia y «organización» en sentido estricto. Dicho esto, se procederá a examinar cada uno de los elementos típicos que la componen.

\section{Agrupación de tres o más personas}

La organización delictiva requiere que la agrupación esté conformada mínimamente por tres sujetos ${ }^{23}$. Según Faraldo (2012), el valor numérico de los individuos se halla estrechamente relacionado con la cualidad de fungibilidad $o$ intercambiabilidad de sus miembros (pág. 67). Desde luego, el incremento significativo de sus integrantes puede ser indicio de la mayor peligrosidad de una organización, por ello de lege ferenda opino que, esta circunstancia debería ser desvalorada como un subtipo específico agravado.

Por otra parte, de la Ley $\mathrm{N}^{\circ} 30077^{24}$ se infiere que la organización, al igual que cualquier otro ente colectivo, «emerge en algún momento, entra en funciones, se afianza o desarrolla, o simplemente se desintegra, y todo ello indudablemente, afecta la intensidad con la que sus rasgos característicos se presentan» (Requejo, 2019, pág. 99).

Cabe destacar que este desarrollo legal no es baladí, pues comprender las fases por las cuales transita una agrupación permite otorgarle un justo alcance al principio de imputación necesaria (Páucar, 2016, pág.

\footnotetext{
23 Estándar mínimo equivale al prescrito en el artículo 2 de la Convención de Palermo (2000).

24 Concretamente de la frase "se crea, existe o funciona"
} (artículo 2.2 Ley $\mathrm{N}^{\circ}$ 30077). 
188). Efectivamente, durante la creación de una organización es posible que la cantidad de sus integrantes sea la mínima, que carezca de jerarquías e incluso que su proyecto delictivo no se encuentre planificado al detalle; en esta fase lo previsible es la persecución punitiva de quién la constituye y/o integra. Empero, cuando la existencia o funcionamiento del colectivo ya se encuentra garantizada, lo razonable es que además de la incorporación de nuevos miembros, se cometan actos de promoción y/u organización en sentido estricto.

\section{Organizaciones estables y organizaciones permanentes}

La descripción de la organización como un ente de carácter estable, permanente o por tiempo indefinido, puede parecer redundante, sin embargo, es menester examinar su concreto significado. Tradicionalmente suele tratarse a la estabilidad como equivalente a permanencia, esto es, como indicador temporal (Anarte, 1999, pág. 33; Castillo, 2005, pág. 59). Sin embargo, nuevas voces plantean distinguir a ambas características, así una vez más resulta esclarecedor el razonamiento de Faraldo (2012), para quien:

La estabilidad es la cualidad que cabe predicar de lo «que se mantiene sin peligro de cambiar, caer o desaparecer» ( $1^{\mathrm{a}}$ acepción del Diccionario de la Lengua Española), mientras que la permanencia es la cualidad de «mantenerse sin mutación en un mismo lugar, estado o calidad» (ídem) (pág. 49).

Del mismo parecer Merino \& Paíno (2016) sostienen que, la continuidad delictiva no alude al tiempo transcurrido sino a la «idea de trascendencia en el tiempo» (pág. 22). Dicho de otro modo, una organización estable es aquella que, dadas las directrices estructurales en que se cimenta o su acceso a recursos propios, tiene «espíritu» de auto conservación; por ello, es válido afirmar que más que una característica se trata de un pronóstico a partir de su capacidad operativa. Nada semejante ocurre en una organización permanente, ya que en ella lo determinante es el lapso transcurrido desde su creación, indistintamente a los delitos cometidos por sus miembros; de ahí, la aclaración «permanente o por tiempo indefinido».

\section{Estructuras jerarquizadas y no jerarquizadas}

Semánticamente, se entiende por tarea al «trabajo que debe hacerse en tiempo limitado» (DRAE), en tanto, por función a la «tarea que corresponde realizar a una institución o entidad, o a sus órganos o personas» (DRAE). Aunque ambas versan sobre actividades, a diferencia de la tarea que nada trasmite sobre la calidad de su ejecutor, la función trasmite que dentro de una organización puede haber integrantes que desempeñen ciertos cargos, es decir, que actúen de modo institucionalizado.

Naturalmente, existe una cercana relación entre la distribución de tareas y funciones y el diseño estructural de una organización, pues «galvanizando este conjunto de individuos debe existir una estructura jerárquica, una división de tareas, grados de especialización $\mathrm{y}$ ciertas reglas (un sistema de premios y castigos) que rigen el comportamiento de la organización y son impuestas de manera coactiva» (Reátegui 2017, pág. 352). En otras palabras, de acuerdo a las tareas y funciones asignadas a sus miembros puede deducirse la clase de estructura del ente colectivo.

De una detenida lectura del artículo 317 del código penal es posible inferir cuáles son las estructuras admitidas por la legislación. Así, cuando el primer subtipo agrava la conducta típica de aquel sujeto que promueve, organiza, constituye o integra una organización desde una concreta posición de liderazgo, jefatura o dirección, implícitamente está revelando que aquella puede presentar una estructura vertical o jerarquizada. En tanto, si ninguno de los sujetos del colectivo ostentase alguna de dichas posiciones, resta asumir que son integrantes de una organización de estructura horizontal.

La división entre estructuras verticales y horizontales, no es una novedad del legislador peruano, sino que esta forma de criminalidad «requiere la configuración de una estructura o diseño organizacional. Ella permite ordenar las actividades y mantiene la cohesión de los grupos criminales. La estructura puede ser rígida o flexible, vertical u horizontal, cerrada o abierta, jerarquizada o descentralizada» (Prado, 2013, pág. 62). Cuando los intervinientes posean un rango equivalente se tratará de una distribución horizontal, en cambio, cuando el rango sea fuertemente jerarquizado, será una 
Systematic interpretation of peruvian criminal law on organized crime: notes of their dogmatic specifications

distribución vertical (Zúñiga, 2009, pág. 129; Merino \& Paíno, 2016, pág. 21).

Así, la exigencia legal que toda organización sea estructurada se desprende de la alusión al reparto de tareas y funciones, sin embargo, ello no significa que toda estructura implique una jerarquía, antes bien puede optarse por una forma más flexible. En el primer caso hablamos de una organización con estructura jerarquizada, y en el segundo, de una organización no jerarquizada (Requejo, 2019, pág. 105) ${ }^{25}$.

\section{Actos de organización, concertación y coordinación}

Conforme a su acepción literal, organizar significa «establecer o reformar algo para lograr un fin, coordinando las personas y los medios adecuados» o «poner algo en orden» (DRAE). Asimismo, concertar es «traer a identidad de fines o propósitos cosas diversas o intenciones diferentes» (DRAE). En tanto, coordinar es «unir dos o más cosas de manera que formen una unidad o un conjunto armonioso» (DRAE).

En el contexto de la delincuencia organizada, Casas (2016) argumenta que:

Por "concertar" debe entenderse el acuerdo entre los miembros de la organización criminal sobre un asunto determinado, ya sea sobre la realización de los hechos delictivos o sobre el fin de lucro que en sí mismo buscan; mientras que "coordinar" debe entenderse como la disposición ordenada de un conjunto de cosas de acuerdo con un método o sistema específico, para la realización de los actos o fines de la organización criminal (pág. 135-136).

Por tanto, que el reparto de las tareas y funciones sea de manera organizada, alude a que las decisiones tomadas no sean espontáneas, sino que respondan a la planificación inicial del ente colectivo; por su parte, que sea de manera concertada, se refiere a que dichas decisiones sean validadas con la aprobación

25 Resulta anecdótico que los jueces de la Corte Superior Nacional de Justicia Penal Especializada (ex Sala Pena Nacional), con motivo de desarrollar su Acuerdo Plenario $\mathrm{N}^{\circ}$ 01-2017-SPN se propusiesen determinar si el elemento de la estructura en una organización delictiva había sido o no derogado por la actual versión del artículo 317 del Código Penal. Sin duda, tal planteamiento carece de relevancia, pues aun cuando el texto legal expresamente no mencionase al vocablo "estructura", desde una perspectiva sistemática fluye que la estructura es un presupuesto intrinseco a la organización. explícita o implícita de los demás miembros; $\mathrm{y}$, por último, que sea de manera coordinada, sugiere que, una vez superada la planificación inicial, las restantes decisiones garanticen la consecución de sus fines ilícitos, preservando su clandestinidad (Requejo, 2019, pág. 108).

En definitiva, que el ente delictivo sea conducido de modo organizado, concertado o coordinado, es una forma de recalcar lo imprescindible que es el elemento estructural. Cabe enfatizar que, en estructuras no jerarquizadas bastará con la concertación, mientras en estructuras jerarquizadas la organización y coordinación puede recaer en los mandos superiores.

\section{Propósito delictivo de la organización}

Sobre las asociaciones ilícitas/organizaciones de la Ley $\mathrm{N}^{\circ} 30077$, la jurisprudencia nacional en su momento sostuvo «resulta raro que, al interior de una organización criminal, la comisión de uno de los comportamientos no esté vinculado a la realización de algún otro y no responda al designio criminal que persigue la organización» (Corte Suprema de la República del Perú, RN N 3308-2010 Lima, fund. 8). Es decir, que todo delito cometido en el seno de una asociación ilícita debe ser resultado de la voluntad colectiva. Al respecto opino que esta afirmación admite excepciones.

Durante la creación de una organización no es indispensable el desarrollo del proyecto delictivo, empero, si el ente colectivo ya se encuentra en funciones lo presumible es que sus miembros cometan delitos. En el primer caso, la subsunción de la conducta recaería en los tipos autónomos de organización; mientras en el segundo caso, de existir regulación legal, en los subtipos específicos agravados por la condición del sujeto activo. Precisamente, esta última figura será aplicada tanto cuando el integrante ejecute el delito valiéndose de los medios materiales de su organización, como cuando se cometa el delito con el propósito de facilitar la existencia y/o funcionamiento de su organización (Requejo, 2019, pág. 184). De modo que, no todo delito perpetrado en el contexto de una organización delictiva es consecuencia del designio común, antes bien, algunos delitos pueden ser motivados por iniciativa propia de sus integrantes. 


\section{FIGURAS TÍPICAS RELATIVAS A LA DELINCUENCIA ORGANIZADA}

\section{Tipos autónomos de organización delictiva}

Esta es la fórmula legal tradicional para afrontar desde el derecho penal a la criminalidad organizada. Por tanto, no es insólito que dos décadas atrás Choclán anticipase que, más allá de lo cuestionable que puede resultar un delito de peligro que anticipa la tutela penal, la real problemática versar en la imprecisión del propio concepto valorativo de organización (pág. 31). Ciertamente en líneas superiores ha podido comprobarse que la delincuencia organizada gravita entorno a la compleja definición de organización delictiva.

Aunado a ello, es también aguda la observación de Silva Sánchez (2015), para quién los tipos autónomos de organización delictiva indefectiblemente implican:

La introducción en el análisis de un bien jurídico supraindividual que, por definición, es lesionado por la estructura organizada con fines delictivos, permite rebajar las exigencias objetivas, tanto en cuanto a la propia organización como en cuanto al comportamiento de los miembros (pág. 105).

En el Código Penal peruano los tipos autónomos se hallan contenidos en el artículo 317, según el cual se prevé una consecuencia punitiva para aquel sujeto que integre, constituya, organice o promueva una organización delictiva. En ellos puede verse plasmada la advertencia de Silva Sánchez, ante lo cual no resta más que delimitar los alcances de cada una de las conductas típicas.

El tipo penal de constituir una organización delictiva se configura al disponer o llevar a cabo todos los actos necesarios para la fundación del ente, esto ocurre, cuando la agrupación de tres o más personas es provista de una estructura afín a sus planes delictivos. Cabe señalar que, cuando el sujeto activo solo se encargue de dotar de operatividad a la organización, será fundador, en cambio, cuando además de ello se desempeñe como integrante, será un fundadorintegrante.

El tipo penal de integrar una organización delictiva consiste en exteriorizar o recibir, de modo explícito o implícito, una señal de conformidad sobre la incorporación del individuo al colectivo. Sobre esto, Maidana (2013) precisa que, los demás miembros deben aceptar al nuevo integrante como su par (pág. 8). Este es un delito de mera actividad y de efectos permanentes, por ende, seguirá consumándose hasta la desafiliación del miembro, sea por renuncia o expulsión.

El tipo penal de promover una organización delictiva implica realizar acciones u omisiones que resulten favorables para el ente colectivo, esto se consigue allanando las dificultades externas que puedan presentarse durante su puesta en funcionamiento. En este ámbito, el promotor de una organización puede ostentar o no la condición de integrante.

Finalmente, el tipo de organizar una organización delictiva consiste en disponer o llevar a cabo todos los actos necesarios para preservar la operatividad del ente delictivo durante su funcionamiento. Según Pacífico (2013), organizador es aquel que se encarga de propiciar nuevas afiliaciones de integrantes, de inspeccionar la gestión del grupo, de actuar en salvaguarda de la estructura y de los recursos propios, interviniendo en la toma de decisiones (pág. 266). A lo anterior se debe añadir que, a diferencia de los líderes, jefes o dirigentes, el organizador de una agrupación puede carecer de tal capacidad de mando.

\section{Subtipos especificos agravados de la delincuencia organizada}

El recurso a los subtipos de agravación es otra de las modalidades tradicionales de la delincuencia organizada. Según Zúñiga (2009) «la solución de dos injustos (...) hace que en los casos en que no resulte posible establecer la imputación de delitos a un miembro de la organización criminal, por lo menos, se le impute el injusto de organización criminal» (pág. 256). Efectivamente, esto determina que los tipos autónomos de artículo 317 actúen como enunciados subsidiarios, no pudiendo presentarse casos de concurso real o ideal con subtipos específicos agravados (Acuerdo Plenario $\mathrm{N}^{\circ}$ 8-2007, fund. 8).

En la legislación peruana, los subtipos específicos agravados de la delincuencia organizada se encuentran presentes tanto en el Código Penal como en leyes especiales. Esta técnica legislativa es aplicada a los delitos criminológicamente más afines a la 
criminalidad organizada. Atendiendo al motivo de su cualificación, estos pueden dividirse en dos clases.

Por un lado, están aquellos que desvaloran al miembro que comete el delito en su desempeño como líder, jefe o dirigente, o al promotor en su desenvolvimiento como financista; cuyo mayor reproche se justifica en la medida que «son los encargados del poder de decisión dentro de la organización criminal y, por lo general, quienes son responsables de las decisiones más importantes del plan criminal, mientras que son otros los que lo ejecutan» (Zúñiga, 2016, pág. 70). A esta clase de subtipos pertenecen los enunciados de los artículos 297 (tráfico ilícito de drogas), 189 (robo agravado), así como el artículo 317 (delitos de organización delictiva).

Por otro lado, están aquellos subtipos específicos que desvaloran al miembro que comete el delito aprovechándose de su condición como tal ${ }^{26}$. Esta medida se justifica dado que, a diferencia de cualquier otro sujeto, el integrante cuenta con la aptitud para hacer más grave la lesión o puesta en peligro de los bienes jurídicos. Cabe agregar que, a este grupo también pertenece el artículo 317 in fine del código penal, el cual realmente se trata de un subtipo específico agravado de los delitos de homicidio y lesiones graves respectivamente (Requejo, 2019, pág. 188).

A pesar que la fórmula de los subtipos específicos agravados se aplica desde hace muchas décadas, nuevos conocimientos justifican su merecida revisión. De acuerdo a Andrade (1997) «la mera organización, como característica del fenómeno delictivo, puede aparecer en cualquier sociedad y estar referida a cualquier delito» (pág. 15), es decir, en la actualidad ya no cabe hacer referencia a un listado de delitos asociados a la criminalidad

26 Dentro del Código Penal estos subtipos específicos agravados pueden adoptar la forma de diversas expresiones, tales como "el agente actúa en calidad de integrante" (véase los artículos 183-a, 186, 257-a, 297, 315-a), "el agente actúa como integrante" (véase los artículos 179, 181, 310-c), "el agente actúe en calidad de integrante" (véase el artículo 189), "actúa en condición de integrante" (véase al artículo 317-a), "comete el delito como integrante" (véase los artículos 162 y 162-b), "el agente es parte de una organización criminal (véase los artículo 153-a y 303-b), "si el agente que comete el delito integra una organización criminal" (véase el artículo 225); también, la descripción "(...) constituyen circunstancias agravantes (...) cuando cualquiera de las conductas descritas se realice (...) por una organización criminal" (véase al segundo párrafo del artículo 272). organizada. Esta tendencia a la generalización, contradice la lógica de estos subtipos agravados; ante ello, de lege ferenda propongo que esta fórmula sea extendida a todos los delitos pluri subjetivos, o en su defecto, sea reemplazada por una técnica legislativa más eficiente.

\section{Especiales circunstancias genéricas de agravación}

Otra modalidad de tipificación incorporada en la legislación penal peruana es la criminalización a través de subtipos genéricos, también conocidos como agravantes especiales o circunstancias genéricas. Esta técnica, a diferencia de los subtipos específicos, carece de autonomía penológica, precisamente debido a ello, puede aplicarse a cualquier tipo penal de la parte especial (Borja, 2015, pág. 37).

Las especiales circunstancias genéricas de agravación están enumeradas en el artículo 22.1 de la Ley $\mathrm{N}^{\circ}$ 30077. De acuerdo a este dispositivo legal, el juzgador aumentará la pena hasta en una tercera parte por encima del límite legal máximo, sin superar los treinta y cinco años de prisión, cuando el integrante de una organización delictiva, persona vinculada a ella o persona que actúe por encargo de la misma, cometa cualquier delito siempre que concurran determinadas condiciones; las cuales, para su mejor comprensión, serán agrupadas por su contenido. El primer grupo de circunstancias alude a la función desempeñada por el sujeto activo, si actúa como líder, jefe, cabecilla, financista de la organización, o incluso si abusa de su condición como funcionario o servidor público (literales $\mathrm{a}, \mathrm{b}$ y c). El segundo grupo concierne al sujeto activo que, para cometer la conducta típica, coacciona a terceras personas o atenta física o psicológicamente contra menores de edad o inimputables (literales d, e y f). Finalmente, el tercer grupo menciona al sujeto activo que, para cometer la conducta típica, hace uso o adquiere armas de guerra o materiales análogos (literales g y h).

Cabe destacar que no corresponde la aplicación de las especiales circunstancias genéricas de agravación si estas ya se encuentran reguladas por subtipos específicos (artículo 22.2 de la Ley $\mathrm{N}^{\circ}$ 30077), ya que esta fórmula legal es subsidiaria respecto a otras. 
En lo particular, la autora valora positivamente que la delincuencia organizada sea abordada a través de técnicas legislativas innovadoras, no obstante, existen motivos para cuestionar el contenido del artículo 22.1 de la Ley $\mathrm{N}^{\circ}$ 30077. En primer lugar, en los literales d, e y $\mathrm{f}$, en vez de agravar circunstancias o elementos accidentales del delito, describen conductas que configuran los delitos de coacción y de lesiones graves (artículos 151 y 121-A del Código Penal). En segundo lugar, en los literales a, b y c, agravan al sujeto activo que se desempeña como líder, jefe, cabecilla y financista de una organización, roles que en su mayoría dan forma a los subtipos específicos agravados de los delitos de organización criminal (segundo párrafo del artículo 317). Ambos casos ponen en evidencia que la incorporación tales circunstancias genéricas es injustificada, pues de no existir, igualmente se hubiesen aplicando las reglas del concurso ideal de delitos (artículo 48 del Código Penal).

\section{Tipos autónomos de banda delictiva}

Después de las organizaciones delictivas, otro ente de la criminalidad organizada son las bandas delictivas. Por ello, no resulta extraño que el artículo 317-B del Código Penal prescriba consecuencias penales para quién «constituya o integre una unión de dos a más personas; que sin reunir alguna o algunas de las características de la organización criminal dispuestas en el artículo 317, tenga por finalidad o por objeto la comisión de delitos concertadamente».

Según la jurisprudencia nacional, la banda es una modalidad rudimentaria de organización delictiva, consistente en «estructuras delictivas de constitución básica y cuyo modo de accionar delictivo carece de complejidad operativa y funcional, al estar dedicada a la comisión de delitos comunes de despojo y mayoritariamente violentos») (Acuerdo Plenario $\mathrm{N}^{\circ}$ 8-2019, fund. 22). Sin perjuicio de esta interpretación, considero que, existen motivos suficientes para sostener que las bandas y las organizaciones delictivas describen distintos fenómenos.

Para empezar, el Código Penal describe a las bandas delictivas de modo positivo y negativo. De acuerdo al primer modo, banda es la unión mínima de dos personas que tienen por finalidad o propósito cometer delitos concertadamente; es decir, que por lo menos, cuente con alguna forma básica de estructura. En tanto, conforme al segundo modo, el concepto de banda se construye al extraer los elementos esenciales de una organización delictiva; así, dándose por descontado que el propio artículo 317B informa sobre la cantidad mínima de sus integrantes, de su estructura y de su propósito delictivo, no resta más que identificar a la banda como una unidad carente de estabilidad o de permanencia, esto es, como una agrupación de carácter transitorio. Precisamente, de las consecuencias jurídicas previstas para las bandas delictivas se infiere que se trata de un injusto penal menos grave.

Asimismo, Prado (2019) destaca que otro criterio para distinguir a la banda de la organización delictiva, es que la primera reprime la comisión de dos conductas típicas (constituir o integrar), mientras que la segunda comprende hasta cuatro formas típicas autónomas (pág.85).

Tampoco es admisible sostener que los delitos ejecutados por miembros de bandas deban subsumirse en subtipos alusivos a organizaciones delictivas ${ }^{27}$; asumir lo contrario significaría menoscabar al principio de legalidad penal, el cual «exige no sólo que por ley se establezcan los delitos, sino también que las conductas prohibidas estén claramente delimitadas por la ley, prohibiéndose tanto la aplicación por analogía» (Tribunal Constitucional, Expediente N ${ }^{\circ}$ 2192-2004-AA/ TC Tumbes, fundamento 4), pues estos subtipos expresamente mencionan a las organizaciones y no a las bandas. Asimismo, esta postura estaría dejando fuera de consideración al principio de proporcionalidad de las penas, ya que induce a tratar de modo equivalente dos injustos penales diferentes. Finalmente, del artículo 317-B no cabe deducir que las bandas delictivas solo involucran la comisión de delitos violentos.

En síntesis, la doctrina jurisprudencial del Acuerdo Plenario $N^{\circ}$ 08-2019 enfatiza en una perspectiva fraccionaria y no sistemática de la delincuencia organizada.

27 Véase el fundamento 23 del Acuerdo Plenario $N^{\circ}$ 08-2019. 


\section{SÍNTESIS DE LOS PRESUPUESTOS DOGMÁTICOS PARA LA INTERPRETACIÓN SISTEMÁTICA}

Cada uno de los preceptos legales antes mencionados dan forma a la legislación penal especializada en delincuencia organizada. Según García-Pablos (1978), esta clase de legislación se caracteriza por su fragmentariedad, pues sus elementos típicos se encuentran dispersos en diferentes secciones del Código Penal (pág. 220). Efectivamente, en el Perú los enunciados relativos a organizaciones y bandas delictivas se hallan tanto en el texto legal de 1991 como en la Ley $N^{\circ}$ 30077. Sin embargo, nuestra legislación no solo se caracteriza por su fragmentariedad sino también por su temporalidad, pues de acuerdo al periodo al cual se haga referencia, cada enunciado posee diferente significado ${ }^{28}$. Justamente dadas estas particularidades, es menester dotar de mayor importancia al estudio de la delincuencia organizada.

A lo largo de este trabajo se han expuesto los presupuestos para la interpretación sistemática de la normativa nacional sobre delincuencia organizada. El primero de ellos consiste en delimitar el contenido de su terminología, para ello es conveniente desarrollar un glosario especializado. El segundo implica examinar cada uno de los instrumentos legales más importantes. El tercero radica en descomponer la técnica legislativa de la delincuencia organizada en un esquema de figuras legales, esto es, en tipos autónomos de organización delictiva, subtipos específicos agravados, especiales circunstancias genéricas de agravación y tipos autónomos de banda delictiva.

Estos presupuestos, por un lado, permiten evaluar las deficiencias y fortalezas de la técnica legislativa aplicada a la criminalidad organizada, y por otro, suponen un estándar de racionalidad y sistematicidad a partir del cual practicar la interpretación. En última instancia, contribuye a fortalecer la capacidad del Estado a través de la actualización de la normativa nacional sobre delincuencia organizada; propósito plasmado en la Política Nacional

28 Por ejemplo, la discrepancia entre la organización delictiva del artículo 2.1 y la asociación ilícita/organización del artículo 317 modificado por la Ley $\mathrm{N}^{\circ} 30077$, desarrollada en la sección 2.2 de este artículo.
Multisectorial de Lucha contra el crimen organizado para el periodo 2019-2030.

\section{CONCLUSIONES}

En el Perú existe una legislación penal especializada en delincuencia organizada, cuyos enunciados legales se encuentran dispersos en el Código Penal de 1991 y en la Ley contra el Crimen Organizado $\mathrm{N}^{\circ} 30077$. Además de los pronunciamientos de la Corte Suprema de la República de las últimas tres décadas.

Los presupuestos para la interpretación sistemática de la normativa nacional sobre delincuencia organizada consisten en: 1) establecer un glosario sobre las expresiones a emplearse, 2) determinar la evolución de los instrumentos legales más relevantes, 3) descomponer a la delincuencia organizada en un esquema de tipos autónomos de organización, subtipos específicos agravados, especiales circunstancias genéricas de agravación y tipos autónomos de banda.

El estudio fraccionario de sus leyes puede conllevar a decisiones cuestionables, por ejemplo, a la incorporación de especiales circunstancias genéricas de agravación redundantes (artículo 22.1 de la Ley $\mathrm{N}^{\circ} 30077$ ), o a la injustificada redefinición jurisprudencial de las bandas delictivas (Acuerdo Plenario $\mathrm{N}^{\circ}$ 08-2019).

\section{FUENTES DE INFORMACIÓN}

\section{Fuentes bibliográficas}

Anarte, E. (1999). Conjeturas sobre la criminalidad organizada. En Ferré, J. \& Anarte, E. (Eds.) Delincuencia organizada: Aspectos penales, procesales y criminológicos (pp. 1357). Huelva, España: Universidad de Huelva.

Andrade, E. (1997). Instrumentos jurídicos contra el crimen organizado. México D.F.; México: Consejo de la Judicatura Federal Poder Judicial de la Federación, UNAM y Senado de la República LVI legislatura.

Borja, E. (2015). La aplicación de las circunstancias del delito: actualizado a la reforma 2015. Valencia; España: Tirant lo Blanch. 
Casas, W. (2016, julio). La criminalidad organizada: sus diferencias con los conceptos de concierto criminal, banda, coautoría y asociación ilícita. Gaceta Penal \& Procesal Penal, 85, 117-144.

Castillo, J. (2005). Asociación para delinquir. Lima, Perú: Editora jurídica Grijley.

Choclán, J. (2000). La organización criminal: tratamiento penal y procesal. Madrid, España: Dykinson.

Faraldo, P. (2012). Asociaciones ilícitas y organizaciones criminales en el código penal español. Valencia, España: Tirant lo Blanch.

García-Pablos, A. (1978). Asociaciones ilícitas en el código penal. Barcelona, España: Bosch.

López-Muñoz, J. (2015). Criminalidad organizada: aspectos jurídicos y criminológicos. Madrid, España: Dykinson S.L.

Maidana, R. (2013). Asociación ilícita. Código penal comentado de acceso libre. Asociación pensamiento penal, 1-27. Recuperado de http://www. pensamientopenal.com. ar/cpcomentado/37788-art-210-210-bisasociacion-ilicita

Merino, J. \& Paíno, F. (2016). Lecciones de criminalidad organizada. Madrid, España: Servicio Publicaciones de la Facultad de Derecho de la Universidad Complutense de Madrid.

Ministerio del Interior (2017). Megaoperativos contra el crimen organizado. Recuperado de https://www.mininter.gob.pe/sites/default/ files/MININTER.\%20Megaoperativos $\% 20$ contra\%20 1\%20 CO.\%20 Primer\%20 a\%C3\%B10\%20de\%20gestion.pdf

Pacífico, P. (2013). Il traffico di sostanze stupefacenti e la legge 9 ottobre 1990, N. 309 [El tráfico de sustancias estupefacientes y la ley 9 de octubre de 1990, N 309]. En Romano, B. \& Tinebra, G. (Dir.). Il diritto penale della criminalità organizzata [El derecho penal de la Criminalidad organizada] (pp. 261-276). Milano, Italia: Giuffrè Editore.

Paúcar, M. (2016). El delito de organización criminal. Lima, Perú: Ideas soluciones Editorial.
Prado, V. (2013). Criminalidad organizada y lavado de activos. Lima, Perú: Idemsa.

Prado, V. (2019). Delitos de organización criminal en el Código Penal peruano. Revista Oficial del Poder Judicial, 9(11), 53-91.

Reátegui, R. (2017). Crimen organizado y Asociación ilícita. En Reátegui, J. \& Reátegui, R. El delito de lavado de activos y el crimen organizado (pp. 279-325). Lima, Perú: A\&C Ediciones.

Requejo, W. (2019). Adecuada sistematización del subtipo de homicidio o lesiones graves agravado por la intervención del integrante de una organización delictiva en la legislación peruana (tesis de pregrado). Universidad de San Martín de Porres, Lima, Perú.

Silva Sánchez, J. (2015). La "intervención a través de organización" ¿una forma moderna de participación en el delito". En Silva Sánchez, J. (Ed.) Delitos de organización (pp. 87-118). Buenos Aires, Argentina: Editorial B de F.

Zúñiga, L. (2009). Criminalidad organizada y sistema de derecho penal: contribución a la determinación del injusto penal de organización criminal. Granada, España: Editorial Comares.

Zúñiga, L. (2016). El concepto de organización criminal de la Ley $\mathrm{N}^{\circ} 30077$ sobre crimen organizado y el delito de asociación ilícita del art. 317 CP: una difícil relación. En Zúñiga, L. (Dir.) \& Mendoza, F. (Coord.). Ley contra el crimen organizado (Ley $N^{\circ}$ 30077): Aspectos sustantivos, procesales y de ejecución penal (pp. 33-139). Lima, Perú: Instituto Pacífico.

\section{Fuentes electrónicas}

Real academia española (2014). «Concertar». En Diccionario de la lengua española $\left(23^{\mathrm{a}} \mathrm{ed}\right.$. $)$. Recuperado de https://dle.rae.es/?id=A7p8kdC

Real academia española (2014). «Coordinar». En Diccionario de la lengua española $\left(23^{a}\right.$ ed. $)$. Recuperado de https://dle.rae.es/?id=Aj3j16N

Real academia española (2014). «Función». En Diccionario de la lengua española $\left(23^{\text {a }}\right.$ ed.). Recuperado de https://dle.rae. es/?id=IbQKTYT 
Real academia española (2014). «Organizar». En Diccionario de la lengua española $\left(23^{\mathrm{a}}\right.$ ed. $)$. Recuperado de https://dle.rae.es/?id=RBn9hqd

Real academia española (2014). «Tarea». En Diccionario de la lengua española $\left(23^{\mathrm{a}}\right.$ ed.). Recuperado de https://dle.rae.es/?id=ZC79NI2

\section{Jurisprudencia}

Corte Superior de Justicia especializada en delitos de crimen organizado y corrupción de funcionarios (2017). Pleno jurisdiccional de la Sala Penal Nacional y Juzgados Penales Nacionales. Acuerdo Plenario $N^{\circ}$ 01-2017SPN.

Corte Suprema del Perú (1999). Recurso de Nulidad N 492-1999 Cono Norte.

Corte Suprema del Perú (2006). Pleno jurisdiccional de las salas penales permanentes y transitorias. Acuerdo Plenario $\mathrm{N}^{\circ}$ 04-2006/ CJ-116.

Corte Suprema del Perú (2007). Pleno jurisdiccional de las salas penales permanentes y transitorias. Acuerdo Plenario $\mathrm{N}^{\circ} 8-2007 / \mathrm{CJ}-$ 116.

Corte Suprema del Perú (2010). Recurso de Nulidad $N^{\circ} 1109-2009$ Lima.

Corte Suprema del Perú (2010). Recurso de Nulidad N² 2780-2009 Lambayeque.

Corte Suprema del Perú (2010). Recurso de Nulidad $\mathrm{N}^{\circ}$ 889-2010 Lima.
Corte Suprema del Perú (2011). Recurso de Nulidad N³308-2010 Lima.

Corte Suprema del Perú (2011). Recurso de Nulidad N 3308-2010 Lima.

Corte Suprema del Perú (2012). Recurso de Nulidad $N^{\circ}$ 583-2011 Ayacucho.

Corte Suprema del Perú (2014). Recurso de Nulidad N ${ }^{\circ} 1531-2014$ Lima.

Corte Suprema del Perú (2014). Recurso de Nulidad $N^{\circ} 886-2014$ Lima.

Corte Suprema del Perú (2015). Casación $N^{\circ}$ 626-2013 Moquegua.

Corte Suprema del Perú (2015). Recurso de Nulidad N 1731-2014 Lima.

Corte Suprema del Perú (2016). Recurso de Nulidad $N^{\circ}$ 2373-2015 Callao.

Corte Suprema del Perú (2017). Casación N ${ }^{\circ}$ 421-2015 Arequipa.

Corte Suprema del Perú (2017). Recurso de Nulidad $\mathrm{N}^{\circ}$ 2367-2016 Nacional.

Corte Suprema del Perú (2017). Recurso de Nulidad N 601-2015 Junín.

Corte Suprema del Perú (2019). Pleno jurisdiccional de las salas penales permanentes y transitorias. Acuerdo Plenario $N^{\circ}$ 8-2019.

Tribunal Constitucional (2004). Expediente $\mathrm{N}^{\circ}$ 2192-2004-AA/TC Tumbes. 